\title{
USO DE INOCULANTES E ADUBO NITROGENADO NA CULTURA DO AMENDOIM (Arachis hypogaea L.)
}

\author{
Ruan Aparecido Biagi Betiol ${ }^{1}$; Godofredo Cesar Vitti Vitti²; Eduardo Zavaschi ${ }^{3}$
}

${ }^{1}$ Graduando em Engenharia Agronômica, ESALQ/USP, Piracicaba, SP, ruanbetiol97@gmail.com; ${ }^{2}$ Professor sênior do departamento de Ciência do Solo, ESALQ/USP, Piracicaba, SP; ${ }^{3}$ Doutor em Solos e nutrição de plantas, consultor agronômico pela empresa Vittagro.

RESUMO: O objetivo do estudo foi avaliar o efeito da inoculação das sementes com Bradyrhizobium sp. e Azospirillum brasilense, e aplicação de nitrogênio em cobertura, aos 70 dias após emergência (DAE), na produtividade da cultura do amendoim. O delineamento experimental foi inteiramente casualizado com 8 tratamentos e 5 repetições. Os tratamentos consistiram na inoculação das sementes com Bradyrhizobium sp. (200g de turfa / $50 \mathrm{~kg}$ de semente), Bradyrhizobium sp. (200 g de turfa / $50 \mathrm{~kg}$ de semente) + Azospirillum brasilense (100 $\mathrm{ml}$ de solução / $50 \mathrm{~kg}$ de semente), Bradyrhizobium sp. (100 g de turfa/ $50 \mathrm{~kg}$ de semente), Bradyrhizobium sp. (100 g de turfa / $50 \mathrm{~kg}$ de semente) + Azospirillum brasilense (100 $\mathrm{ml}$ de solução / $50 \mathrm{~kg}$ de semente), Azospirillum brasilense (100 ml de solução / $50 \mathrm{~kg}$ de semente), aplicação de 65 e $130 \mathrm{~kg} \mathrm{ha}^{-1} \mathrm{~N}$ via ureia aos 70 DAE, e controle. A inoculação com Bradyrhizobium sp., na dose de 200 g / 50 kg de semente, proporcionou maior número e peso de nódulos por planta. $\mathrm{O}$ teor de nitrogênio foliar foi maior nos tratamentos com a aplicação de nitrogênio mineral. A inoculação, co-inoculação e a aplicação de $65 \mathrm{~kg} \mathrm{ha}^{-1} \mathrm{~N}$ em cobertura não resultaram em aumento de produtividade de grãos e vagens. A aplicação de $130 \mathrm{~kg} \mathrm{ha}^{-1}$ $\mathrm{N}$ teve efeito significativo no aumento da produtividade de grãos e vagens.

Palavras-Chave: amendoim, Bradyrhizobium sp., Azospirillum brasilense, e nitrogênio.

\section{INTRODUÇÃO}

O amendoim por ser uma espécie leguminosa, possui a capacidade de associação com bactérias fixadoras de N (Bradyrhizobium sp.), o que lhe permite eficiência no processo de absorção desse nutriente. Porém, a prática de inoculação do amendoim não é muito comum, uma vez que esse normalmente encontra-se nodulado devido a suas raízes serem colonizadas por uma ampla faixa de rizóbio tropical (THIES et al., 1991). Vários fatores podem determinar a necessidade de inoculação em regiões tropicais, tais como a reduzida população de rizóbio nativo do solo, principalmente em áreas submetidas a temperaturas elevadas ou à baixa umidade do solo, ou áreas sem histórico de cultivo anterior com leguminosas (MARTINS et al., 1997).

Dentre as rizobactérias utilizadas na inoculação de outras espécies leguminosas, se destacam as bactérias do gênero Azospirillum (CASSÁN et al., 2008). Neste contexto, iniciou-se, nos últimos anos 
no Brasil, os estudos com co-inoculação de Bradyrhizobium sp. e Azospirillum brasilense nas culturas de soja e de feijão, buscando ganhos em nodulação e suprimento de $\mathrm{N}$, e maior produtividade de grãos (HUNGRIA et al., 2013). Nos casos em que se tem utilizado A. brasilense em leguminosas, os efeitos benéficos da associação com o Bradyrhizobium se devem, na maior parte, a capacidade que a rizobactéria tem de fixar $\mathrm{N}_{2}$ atmosférico (HUERGO et al., 2008), produzir hormônios vegetais (BOTTINI et al., 1989) e aumentar a atividade da enzima nitrato redutase (CASSÁN et al., 2008).

Outra forma de fornecer nitrogênio para a cultura do amendoim é a utilização de adubos minerais. LANIER et al. (2005) compararam a aplicação de $\mathrm{N}$ fertilizante em seis lugares diferentes, utilizando doses crescentes de $\mathrm{N}$ fertilizante $\left(23,70,115,160\right.$ e $210 \mathrm{~kg} \mathrm{ha}^{-1}$ de $\mathrm{N}$ na forma de sulfato de amônio) e a aplicação de inoculantes na cultura do amendoim, constataram que a produção de vagens foi diretamente proporcional às doses de $\mathrm{N}$ fertilizante utilizadas, muito embora a produção nos tratamentos inoculados tenha sido maior do que com a aplicação $160 \mathrm{~kg} \mathrm{ha}^{-1}$ de $\mathrm{N}$ fertilizante.

O objetivo do estudo foi avaliar o efeito da inoculação das sementes com Bradyrhizobium sp. e Azospirillum brasilense e suas combinações, e a aplicação de nitrogênio em cobertura aos 70 DAE, na produtividade da cultura do amendoim.

\section{MATERIAL E MÉTODOS}

O experimento foi desenvolvido em área de reforma de cana-de-açúcar no município de Dois Córregos-SP (latitude 22²1'58" Sul; longitude 48²2'49" Oeste, $673 \mathrm{~m}$ ). O solo da área experimental é classificado como Argissolo Vermelho distrófico típico, de textura média. O clima na região é classificado como Cfa, segundo Köppen e a pluviosidade média do local é de $1301 \mathrm{~mm}$.

O delineamento experimental adotado foi o inteiramente casualizado com 8 tratamentos e 5 repetições. Cada parcela tinha 5,4 metros de largura, com seis linhas de plantio de espaçamento $0,90 \mathrm{~m}$ e 14 metros de comprimento. Os tratamentos consistiram na aplicação de inoculantes (Bradyrhizobium $s p$ e/ou Azospirillum brasilense) via tratamento de sementes e adubação de cobertura de N (65 e 130 $\mathrm{kg} \mathrm{ha}^{-1} \mathrm{~N}$ ) via ureia. A inoculação das sementes com Bradyrhizobium sp. foi realizada com o inoculante turfoso contendo a estirpe SEMIA 6144, na dose de 100 e $200 \mathrm{~g}$ por $50 \mathrm{~kg}$ de sementes. Para a inoculação com Azospirillum brasilense foi utilizado o inoculante líquido na dose de $100 \mathrm{~mL}$ por $50 \mathrm{~kg}$ de sementes. A aplicação de $\mathrm{N}$ foi realizada na área total da parcela $70 \mathrm{DAE}$ da cultura do amendoim (Tabela 1). 
16 e 17 de agosto de 2018, centro de convenções da FCAV/UNESP - Câmpus de Jaboticabal, SP

Tabela 1. Descrição dos tratamentos

\begin{tabular}{ccc}
\hline & Tratamentos & Doses \\
\hline T1 & Bradyrhizobium sp. & $200 \mathrm{~g}$ \\
T2 & Bradyrhizobium sp. + Azospirillum brasilense & $200 \mathrm{~g}+100 \mathrm{ml}$ \\
T3 & Controle & ------ \\
T4 & Bradyrhizobium sp. & $100 \mathrm{~g}$ \\
T5 & Bradyrhizobium sp. + Azospirillum brasilense & $100 \mathrm{~g}+100 \mathrm{ml}$ \\
T6 & Azospirillum brasilense & $100 \mathrm{ml}$ \\
T7 & Ureia & $65 \mathrm{~kg} \mathrm{ha}^{-1} \mathrm{~N}^{2}$ \\
T8 & Ureia & $130 \mathrm{~kg} \mathrm{ha}^{-1} \mathrm{~N}^{2}$ \\
\hline
\end{tabular}

${ }^{1}$ Dose usada para cada $50 \mathrm{Kg}$ de semente $;{ }^{2}$ Aplicação na área total da parcela.

A cultivar utilizada foi a IAC-OL3 (ciclo médio de 130 dias), com estande médio de 12 plantas por metro. O plantio foi realizado 02 de novembro de 2017.

Realizou-se as práticas adequadas de calagem e gessagem para a cultura do amendoim. A adubação mineral foi feita de maneira localizada no sulco de plantio da cultura do amendoim com 10, 75 e $25 \mathrm{~kg} \mathrm{ha}^{-1}$ de N, $\mathrm{P}_{2} \mathrm{O}_{5}$ e $\mathrm{K}_{2} \mathrm{O}$ respectivamente. Houve também a aplicação do boro, na dose de 0,5 $\mathrm{kg} \mathrm{ha}^{-1}$, via solo em área total na pré-emergência da cultura do amendoim.

Para verificar o efeito dos tratamentos, realizou-se diferentes avaliações de diagnose. Inicialmente foi feita a análise foliar, conforme MALAVOLTA et al. (1997), coletando-se as folhas do ápice das plantas aos 106 dias após plantio (DAP) da cultura. Para pesagem, retirou-se a parte aérea de cinco plantas de cada parcela aos 111 DAP da cultura, e para a separação da parte aérea foi usado o ponto de inserção cotiledonar como ponto de corte. A contagem e pesagem do número total de nódulos foram feitas aos 111 DAP da cultura. Para as avaliações de produtividade, realizou-se o arranquio 09 de março de 2018, e a colheita 24 de março de 2018, época que foram colhidas as vagens das plantas localizadas nas 4 linhas centrais, fazendo-se a correção da massa dos grãos considerando teor de água de $11 \%$. Posteriormente, houve a contagem do total de vagens e grãos de cinco plantas de cada parcela. No final das avaliações, ocorreu a contagem e pesagem de 100 grãos e 20 vagens, cuja massa foi corrigida considerando teor de água de $11 \%$.

Os resultados obtidos foram submetidos a análise de variância e as médias comparadas pelo teste LSD a 10\% de probabilidade, com o auxílio do programa estatístico SISVAR.

\section{RESULTADOS E DISCUSSÃO}

A aplicação de $130 \mathrm{~kg} \mathrm{ha}^{-1} \mathrm{~N}$ aumentou a produtividade $13,16 \%$ em relação ao controle (Tabela 2). A inoculação e a co-inoculação não afetaram a produtividade do amendoim, possivelmente por não serem tão eficientes quanto as estirpes de rizóbios nativos presentes no solo em fornecer o nitrogênio para a cultura. 
A aplicação de $\mathrm{N}$ em cobertura proporcionou maior teor de $\mathrm{N}$ foliar (Tabela 2), apesar da concentração do nutriente na folha estar dentro da faixa adequada (30-45 $\mathrm{g} \mathrm{kg}^{-1}$ ) em todos os tratamentos. O número de nódulos por planta e o peso de nódulos por planta foi maior onde realizouse a inoculação com Bradyrhizobium sp. na dose de $200 \mathrm{~g}$ de turfa / $50 \mathrm{~kg}$ de semente, possivelmente por fornecer maior quantidade de células viáveis para a infecção da raiz do amendoim. Entretanto, pode-se observar redução do peso de nódulos por planta onde houve aplicação de $\mathrm{N}$ em cobertura, possivelmente em função do menor custo energético do nutriente oriundo da ureia em relação ao do processo simbiótico.

Tabela 2. Valores médios e significância para produtividade, teor de $\mathrm{N}$ foliar, $\mathrm{n}^{\mathrm{o}}$ total de nódulos por planta e peso de nódulos por planta.

\begin{tabular}{|c|c|c|c|c|}
\hline Tratamentos & $\begin{array}{l}\text { Produtividade } \\
\qquad\left(\mathrm{kg} \mathrm{ha}^{-1}\right)\end{array}$ & $\begin{array}{l}\text { Teor de } \mathrm{N} \text { foliar } \\
\qquad\left(\mathrm{g} \mathrm{kg}^{-1}\right)\end{array}$ & $\begin{array}{l}\mathrm{N}^{\mathrm{o}} \text { total de nódulos } \\
\text { por planta }\end{array}$ & $\begin{array}{l}\text { Peso de nódulos } \\
\text { por planta }^{-1}(\mathrm{mg})\end{array}$ \\
\hline T1 & $5198 \mathrm{abc}$ & $35,8 \mathrm{de}$ & $201,8 \mathrm{a}$ & $191,2 \mathrm{a}$ \\
\hline $\mathrm{T} 2$ & $5119 \mathrm{bc}$ & $34,0 \mathrm{e}$ & $199,6 \mathrm{ab}$ & $128,6 \mathrm{ab}$ \\
\hline $\mathrm{T} 3$ & 5039 bc & $37,2 \mathrm{~cd}$ & $118,6 \mathrm{ef}$ & $146,0 \mathrm{ab}$ \\
\hline $\mathrm{T} 4$ & $4761 \mathrm{c}$ & $37,9 \mathrm{~cd}$ & $162,0 \mathrm{bcd}$ & $151,5 \mathrm{ab}$ \\
\hline $\mathrm{T} 5$ & $4801 \mathrm{c}$ & $39,0 \mathrm{bc}$ & $176,4 \mathrm{abc}$ & $102,8 \mathrm{bc}$ \\
\hline T6 & $4698 \mathrm{c}$ & $37,1 \mathrm{~cd}$ & $108,8 \mathrm{f}$ & $131,2 \mathrm{bc}$ \\
\hline $\mathrm{T} 7$ & $5476 \mathrm{ab}$ & $41,4 \mathrm{ab}$ & 129,2 def & $54,4 \mathrm{c}$ \\
\hline $\mathrm{T} 8$ & $5702 \mathrm{a}$ & $43,5 \mathrm{a}$ & 149,6 cde & $52,6 \mathrm{c}$ \\
\hline CV\% & 9,96 & 7,07 & 22,63 & 52,25 \\
\hline P-valor & 0,0397 & 0,0001 & 0,0006 & 0,0231 \\
\hline
\end{tabular}

Médias seguidas de mesma letra minúscula na coluna não diferem entre si pelo teste de LSD

O peso de 100 grãos foi maior onde houve a co-inoculação da cultura $(100 \mathrm{~g}+100 \mathrm{ml} / 50 \mathrm{~kg}$ de semente) e o fornecimento de $\mathrm{N}$ em cobertura. Não houve efeito da inoculação, co-inoculação ou aplicação de nitrogênio para os parâmetros de peso de 20 vagens e ${ }^{0}$ de vagens por planta (Tabela 3 ). A co-inoculação com Bradyrhizobium sp. e Azospirillum brasilense $(200 \mathrm{~g}+100 \mathrm{ml} / 50 \mathrm{~kg}$ de semente) teve efeito positivo no número de grãos por vagem. $\mathrm{O}$ fornecimento de $\mathrm{N}$ mineral resultou em aumento da biomassa de parte aérea das plantas de amendoim (Tabela 3), possivelmente em função da maior absorção de N, nutriente esse essencial para o desenvolvimento vegetativo. 
16 e 17 de agosto de 2018, centro de convenções da FCAV/UNESP - Câmpus de Jaboticabal, SP

Tabela 3. Valores médios e significância para peso de 100 grãos, peso de 20 vagens, $n^{\circ}$ de vagens por planta, $n^{\circ}$ de grãos por vagem e peso parte aérea por planta.

\begin{tabular}{cccccc}
\hline Tratamentos & $\begin{array}{c}\text { Peso de } \\
\text { 100 grãos (g) }\end{array}$ & $\begin{array}{c}\text { Peso de } \\
\text { 20 vagens }(\mathrm{g})\end{array}$ & $\begin{array}{c}\mathrm{N}^{\mathrm{o}} \text { de vagens } \\
\text { planta }^{-1}\end{array}$ & $\begin{array}{c}\mathrm{N}^{\mathrm{o}} \text { de grãos } \\
\text { vagem }^{-1}\end{array}$ & $\begin{array}{c}\text { Peso parte aérea } \\
\text { planta }^{-1}(\mathrm{~g})\end{array}$ \\
\hline $\mathrm{T} 1$ & $65,9 \mathrm{ab}$ & 30,9 & 47,6 & $1,78 \mathrm{~b}$ & $17,7 \mathrm{bc}$ \\
$\mathrm{T} 2$ & $62,2 \mathrm{~b}$ & 30,4 & 44,7 & $1,95 \mathrm{a}$ & $20,3 \mathrm{abc}$ \\
$\mathrm{T} 3$ & $65,3 \mathrm{ab}$ & 29,3 & 38,3 & $1,79 \mathrm{~b}$ & $19,2 \mathrm{bc}$ \\
T4 & $64,1 \mathrm{ab}$ & 29,0 & 50,9 & $1,88 \mathrm{ab}$ & $22,8 \mathrm{ab}$ \\
T5 & $67,5 \mathrm{a}$ & 30,7 & 38,8 & $1,79 \mathrm{~b}$ & $15,9 \mathrm{c}$ \\
T6 & $65,8 \mathrm{ab}$ & 29,7 & 42,0 & $1,86 \mathrm{ab}$ & $21,6 \mathrm{abc}$ \\
T7 & $66,6 \mathrm{a}$ & 31,8 & 42,8 & $1,84 \mathrm{ab}$ & $26,0 \mathrm{a}$ \\
T8 & $66,8 \mathrm{a}$ & 28,1 & 43,2 & $1,76 \mathrm{~b}$ & $23,6 \mathrm{ab}$ \\
\hline CV\% & 6,05 & 12,43 & 31,74 & 8,08 & 29,92 \\
P-valor & 0,5133 & 0,8214 & 0,8523 & 0,4979 & 0,2415 \\
\hline
\end{tabular}

Médias seguidas de mesma letra minúscula na coluna não diferem entre si pelo teste de LSD.

\section{CONCLUSÃO}

A inoculação com Bradyrhizobium sp., na dose de $200 \mathrm{~g} / 50 \mathrm{~kg}$ de semente, proporcionou maior número e peso de nódulos por planta.

$\mathrm{O}$ teor de nitrogênio foliar foi maior com a aplicação de nitrogênio mineral.

A inoculação, co-inoculação e a aplicação de $65 \mathrm{~kg} \mathrm{ha}^{-1} \mathrm{~N}$ em cobertura não resultaram em aumento de produtividade de grãos e vagens.

A aplicação de $130 \mathrm{~kg} \mathrm{ha}^{-1} \mathrm{~N}$ teve efeito significativo no aumento da produtividade de grãos e vagens.

\section{REFERÊNCIAS BIBLIOGRÁFICAS}

BOTTINI, R.; FULCHIERI, M.; PEARCE, D.; PHARIS, R. Identification of gibberelins A1, A3, and iso-A3 in cultures of A. lipoferum. Plant Physiology, Amsterdam, v. 90, p. 45-47, 1989.

CASSÁN, F.; SGROY, V.; PERRIG, D.; MASCIARELlI, O.; LUNA, V. Producción de fitohormonas por Azospirillum sp. Aspectos fisiológicos y tecnológicos de la promoción del crecimiento vegetal. In: CASSÁN, F. D.; SALAMONE, I. G. (Ed.) Azospirillum sp.: cell physiology, plant interactions and agronomic research in Argentina. Buenos Aires: Asociación Argentina de Microbiologia, 2008. p. 61-86.

HUERGO, L. F.; MONTEIRO, R. A.; BONATTO, A. C.; RIGO, L. U.; STEFFENS, M. B. R.; CRUZ, L. M.; CHUBATSU, L. S.; SOUZA, E. M.; PEDROSA, F. O. Regulation of nitrogen fixation in Azospirillum brasilense. In: CASSÁN, F. D.; GARCIA DE SALAMONE, I. Azospirillum sp.: cell physiology, plant interactions and agronomic research in Argentina. Buenos Aires: Asociación Argentina de Microbiologia, 2008. p. 17-35. 
HUNGRIA, M.; NOGUEIRA, M. A.; ARAUJO, R. S. Coinoculation of soybeans and common beans with rhizobia and azospirilla: strategies to improve sustainability. Biology Fertility of Soils, Amsterdam, v. 49, n. 7, p. 791-801, 2013.

LANIER, J. E. et al. Peanut response to inoculation and nitrogen fertilizer. American Society of Agronomy, Madison, v.97, p.79-84, 2005.

MALAVOLTA, E.; VITTI, G.; OLIVEIRA, S. A. Avaliação do estado nutricional das plantas: princípios e aplicações. 2. ed. Revisada e atualizada. Piracicaba: POTAFOS. 1997. 319 p.

MARTINS, L.M.U. et al. Growth characteristics and symbiotic efficiency of rhizobia isolated from cowpea nodules of the northeast of Brazil. Soil. Biol. Biochem., Oxford, v. 29, p. 1005-1010, 1997.

THIES, J.E. et al. Subgroups of de Cowpea miscellany: symbiotic specificity within Bradyrhizobium spp. for Vigna unguiculata, Phaseolus lunatus, Arachis hypogaea and Macroptilium atropurpureum. Appl. Environ. Microbiol., Washington, DC, v. 57, p. 1540-1545, 1991. 